\title{
Study on Mechanical Properties of Concrete with Different Steel Fiber Content
}

\author{
R Z Zhou*, Y Jin \\ College of Civil Engineering, Bengbu University, Bengbu, \\ Anhui 233030, China
}

\begin{abstract}
To discuss the mechanical properties of concrete with different content of steel fiber. Two grades of concrete were prepared, and the effects of different content and length of steel fiber on slump, pore structure, compressive strength, splitting strength, flexural toughness and impact resistance of concrete were studied. The fluidity of steel fiber reinforced concrete decreased with the increase of steel fiber content, and the concrete with long steel fiber decreased more than that with short steel fiber. With the increase of steel fiber content, the compressive strength, splitting strength, bending toughness and impact resistance of steel fiber reinforced concrete were improved to varying degrees. The splitting tensile strength increases fastest when the volume content of steel fiber was $1.0 \% \sim 1.5 \%$, and the flexural strength increases fastest when the volume content of steel fiber was 1.0\% 2.5\%. When the fiber was stressed, it gave full play to its strong tensile capacity and shares the tensile force for concrete materials. According to the comprehensive economy, the optimum steel fiber content is $2 \% \sim 3 \%$, which provides a basis for subsequent experimental research and construction production.
\end{abstract}

\section{INTRODUCTION}

Because of the low tensile strength of concrete, cracks will appear in the tensile zone of concrete structure, which will accelerate the carbonization of concrete, and the bearing capacity and service life of concrete structure will decrease with the expansion of cracks [1]. Compared with ordinary concrete, steel fiber reinforced concrete has the advantages of high tensile strength, bending strength and shear strength, and can significantly improve the crack resistance, toughness, impact resistance and durability of concrete [2, 3]. It is very difficult to greatly improve the compressive strength of ordinary concrete due to the limitations of material properties and construction technology. Concrete is characterized by poor ductility, high brittleness, low ratio of tensile strength to compressive strength and low fracture toughness. Therefore, it is of great significance to reduce the brittleness and improve the toughness of concrete for improving its impact resistance, penetration resistance and

*Corresponding Author: baizhan302598@yeah.net 
durability. Compared with traditional concrete, ultra-high-performance concrete has superior mechanical properties in tensile strength, compressive strength, corrosion resistance, fatigue resistance, durability and frost resistance, its compressive strength can reach 150 800 MPa, and its fracture energy can reach $20 \sim 40 \mathrm{~kJ} / \mathrm{m} 2$ [4]. In recent 20 years, high-strength concrete, high-performance concrete and high-durability concrete have developed rapidly, while steel fiber concrete has been widely used in various engineering structures because of its obvious reinforcement, toughening and crack resistance $[5,6]$. Nowadays, adding fiber into concrete can increase tensile strength, flexural strength, impact resistance and toughness, and even help to crack resistance, which makes to the application and research of concrete enter a new stage. After the emergence of steel fiber reinforced concrete, the research on steel fiber reinforced concrete has never stopped. Since the 1920s, a large number of experimental studies on steel fiber reinforced concrete (SFRC) have been carried out in Europe and America, and relevant research results and technical patents have been published successively. Algburi et al. [7] carried out a basic mechanical test research on steel fiber reinforced concrete with steel fiber volume content of $0 \%, 0.75 \%$ and $1.0 \%$, and pointed out that steel fiber can enhance the modulus and strength of concrete; Relevant data $[8,9]$ shows that the compressive strength of steel fiber reinforced concrete with $1 \% \sim 2 \%$ volume ratio increases by $10 \% \sim 30 \%$ compared with matrix concrete. Fu et al. [10] used the morphology analysis method to link the difference of steel fiber number on different fracture surfaces with the mechanical properties and anisotropy of SFRC and found that flexural toughness index and bearing capacity change coefficient of steel fiber reinforced high-strength concrete increased with the increase of steel fiber volume ratio. The research of Babaie et al. [11] shows that steel fiber can effectively prevent the shrinkage strain of concrete and reduce the shrinkage of concrete. In the process of composite material formation and stress failure, steel fiber can effectively reduce the strength factor of the stress field at the crack tip, restrict the development of micro-cracks and block the generation of macro cracks, thus achieving the effect of strengthening and toughening concrete matrix.

A large number of studies show that steel fiber can significantly improve the mechanical properties of ultra-high-performance concrete, such as tensile strength and compressive strength. In order to accurately analyze the influence of steel fiber on the mechanical properties of ultra-high-performance concrete, this paper carried out an experimental research on the compressive strength, tensile strength and flexural strength of ultra-high performance concrete specimens with different volume content of steel fiber.

\section{EXPERIMENT DESIGN}

2.1. Test Materials and Mixture Ratio

2.1.1. Test material

Ordinary Portland cement P.O42.5R produced by a company was used, and the fineness of cement is $3400 \mathrm{~cm} 2 / \mathrm{g}$; The initial setting time is 2 hours and 40 minutes, and the final setting time is 3 hours and 40 minutes. The water consumption of standard consistency is $27 \%$; The loss on ignition is $0.5 \%$. As the gravel surface is rough and angular, it has a good mechanical locking effect with other materials in steel fiber reinforced concrete. At the same time, as 
the specific surface area of gravel is larger than that of pebble, more cement slurry is generally needed, and its fluidity is worse than that of pebble. Generally, the particle size of coarse aggregate shall not exceed 2/3 of the length of steel fiber, and the maximum particle size shall not exceed $20 \mathrm{~mm}$. A kind of wave-shaped steel fiber produced by a company was used, and its quality meets the technical requirements of Steel Fiber Concrete (JG /T3064-1999), with a length of $30 \mathrm{~mm}$, an aspect ratio of 50, and a rectangular cross section. Its physical properties are shown in Table 1 . The water reducing agent is naphthalene based high-efficiency water reducing agent, which is yellow brown and powdery, and its water reducing rate is over $20 \%$.

Table 1 Physical properties of steel fiber

\begin{tabular}{llllll}
\hline Type & $\begin{array}{l}\text { Length- } \\
\text { diameter } \\
\text { ratio }\end{array}$ & $\begin{array}{l}\text { Tensile strength } \\
/ \mathbf{N} \cdot \mathbf{m m}^{-2}\end{array}$ & $\begin{array}{l}\text { Modulus of } \\
\text { elasticity } \\
/ \mathbf{N} \cdot \mathbf{m m}^{-2}\end{array}$ & $\begin{array}{l}\text { 10D standard } \\
\text { extension rate } \\
/ \%\end{array}$ & $\begin{array}{l}\mathbf{9 0 0} \\
\text { flexure }\end{array}$ \\
\hline Shear & 50 & More than 480 & 200000 & 10 & $\begin{array}{l}\text { More than } 5 \\
\text { times }\end{array}$ \\
\hline
\end{tabular}

\subsubsection{Mix ratio}

The benchmark concrete grades used in the test are C40 and C60 respectively, and the matching examples are shown in Table 2.

Table 2 Mix proportion of concrete of different grades

\begin{tabular}{cccccccc}
\hline & $\begin{array}{c}\text { Cement } \\
/ \mathbf{k g}\end{array}$ & $\begin{array}{c}\text { Sand } \\
/ \mathbf{k g}\end{array}$ & $\begin{array}{c}\text { Stone } \\
/ \mathbf{k g}\end{array}$ & $\begin{array}{c}\text { Water } \\
\mathbf{/ k g}\end{array}$ & $\begin{array}{c}\text { Water } \\
\text { reducing } \\
\text { agent/\% }\end{array}$ & $\begin{array}{c}\text { Fiber } \\
\text { type } \\
\mathbf{/ m m}\end{array}$ & $\begin{array}{c}\text { Volume content of } \\
\text { fiber } \\
/ \mathbf{m}\end{array}$ \\
\hline $\mathrm{C} 40$ & 400 & 660 & 1300 & 150 & 1.0 & 35 & $0.3,0.5,0.7,1.0,1.3$ \\
$\mathrm{C} 40$ & 400 & 660 & 1300 & 150 & 1.0 & 50 & 1.2 \\
$\mathrm{C} 60$ & 480 & 740 & 1050 & 150 & 1.5 & 35 & $0.3,0.5,0.7,1.0,1.3$ \\
$\mathrm{C} 60$ & 480 & 740 & 1050 & 150 & 15 & 50 & 1.2 \\
\hline
\end{tabular}

\subsection{Experimental Method}

In this test, cube specimens with compressive strength and splitting tensile strength of 150 $\mathrm{mm} \times 150 \mathrm{~mm} \times 150 \mathrm{~mm}$ were used, and beam specimens with flexural strength of $150 \mathrm{~mm} \times$ $150 \mathrm{~mm} \times 550 \mathrm{~mm}$ were used. The forming and curing of concrete were completed in the laboratory with reference to GB/T50081-2002 Standard for Test Methods of Mechanical Properties of Ordinary Concrete. In this experiment, four kinds of specimens with different content of fiber were made, each of which included 6 compressive specimens and split tensile specimens, with dimensions of $150 \mathrm{~mm} \times 150 \mathrm{~mm} \times 150 \mathrm{~mm}$. The cube compressive strength and splitting tensile strength of each specimen were tested on a universal testing machine according to the method specified in CECS13:89 "Test Methods for Steel Fiber Concrete".

Several approaches, from analytical to computational models, are possible to evaluate the reliability and vulnerability of the structural systems. 


\subsection{Test Material Preparation}

\subsubsection{Mixing of Steel Fiber Reinforced Concrete}

There are three main mixing processes of steel fiber reinforced concrete: first dry and then wet mixing process, wet mixing process and sectional feeding mixing. In this test, a forced mixer was used. First, the coarse aggregate and fine aggregate were added into the mixer to mix evenly, then cement and steel fiber were added in turn for dry mixing, so that the steel fiber was evenly distributed in the mixture, and then water was slowly added for mixing. During the test, due to the small amount and uniform dispersion of steel fiber, no clustering problem was found.

\subsubsection{Manufacture and Maintenance of Specimen}

In order to ensure the mixing effect of steel fiber recycled concrete, the whole mixing process was divided into two sub-processes. Firstly, sand, gravel, recycled aggregate and cement were mixed, and then mixed with steel fiber for the second time. Finally, water was added and mixed to synthesize steel fiber recycled concrete. The specimen was molded by plate vibration, and the specimen was removed after being placed outdoors for hours. After numbering, it was put into the standard curing room for curing.

\section{TEST RESULTS AND DISCUSSION}

\subsection{Test Result}

Compressive strength of concrete cube is calculated according to equation (1), and splitting tensile strength is calculated according to equation (2) [12]:

$$
\begin{gathered}
f_{c c}=\frac{F}{A} \\
f_{t s}=0.637 \frac{F}{A}
\end{gathered}
$$

where $f_{c c}$ is the compressive strength of concrete cube specimen (MPa); $f_{t s}$ is splitting tensile strength (MPa); $F$ is the failure load of the specimen (n); $A$ is the bearing area of the specimen $(\mathrm{mm} 2)$.

\subsubsection{Influence of Steel Fiber Content on Compressive Strength of Concrete}

It is seen from Table 3 that the cube compressive strength and axial compressive strength of concrete gradually increased with the increase of steel fiber volume content. When the volume content of steel fiber increased from 0 to $0.4 \%$, the strength increased rapidly at first, and then increased steadily with the volume content of steel fiber. When the volume content of steel fiber increased from $0.4 \%$ to $2.8 \%$, the cube compressive strength increased by 7.44\% 23.39\% and the axial compressive strength increased by $8.02 \% \sim 24.61 \%$. 
Table 3 Influence of steel fiber content on compressive strength of concrete

\begin{tabular}{lllll}
\hline No. & $\begin{array}{l}\text { Compressive } \\
\text { strength of cube } \\
\text { /MPa }\end{array}$ & $\begin{array}{l}\text { Improvement rate of } \\
\text { cube compressive } \\
\text { strength } \\
/ \%\end{array}$ & $\begin{array}{l}\text { Axial compressive } \\
\text { strength } \\
\text { /MPa }\end{array}$ & $\begin{array}{l}\text { Increase rate of } \\
\text { axial compressive } \\
\text { strength } \\
\text { /\% }\end{array}$ \\
\hline 1 & 130.61 & - & 110.67 & - \\
\hline 2 & 141.02 & 8.24 & 120.41 & 8.07 \\
\hline 3 & 147.66 & 10.24 & 128.92 & 10.64 \\
\hline 4 & 148.1 & 18.63 & 130.07 & 18.57 \\
\hline
\end{tabular}

\subsubsection{Influence of Steel Fiber on Splitting Strength of Concrete}

Figure 1. shows that the splitting strength of concrete gradually increases with the increase of volume content of steel fiber. When the volume content of steel fiber was $1.2 \%$, the splitting strength of C40 and C60 concrete increased by $34.6 \%$ and $38.2 \%$ respectively. It can be seen from Figure 2 that the splitting strength of concrete increased with the increase of steel fiber length. When the volume content of steel fiber was the same as $1.5 \%$, the splitting strength of C40 and C60 concrete with $50 \mathrm{~mm}$ steel fiber was 4.4\% and 5.9\% higher than that of concrete with $35 \mathrm{~mm}$ steel fiber.

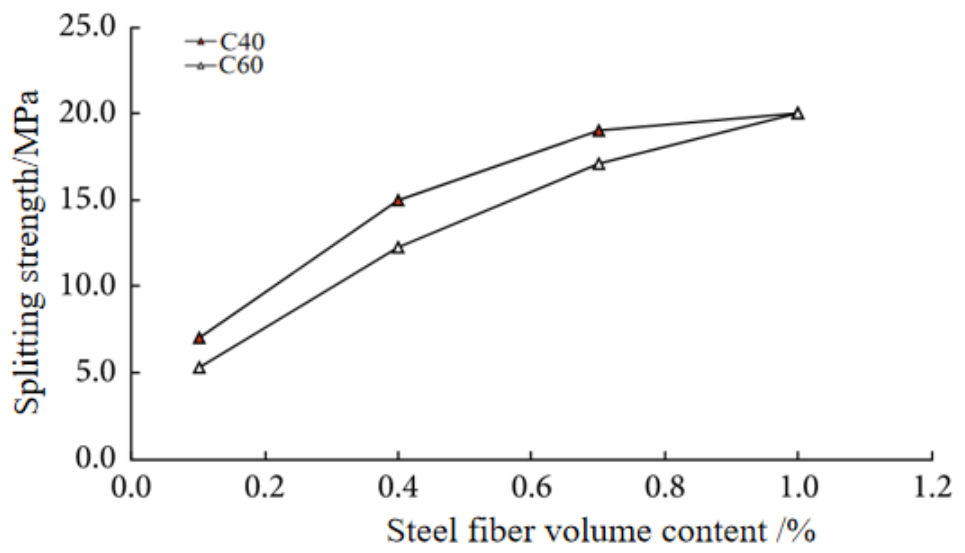

Figure 1. Effect of steel fiber content on splitting strength 


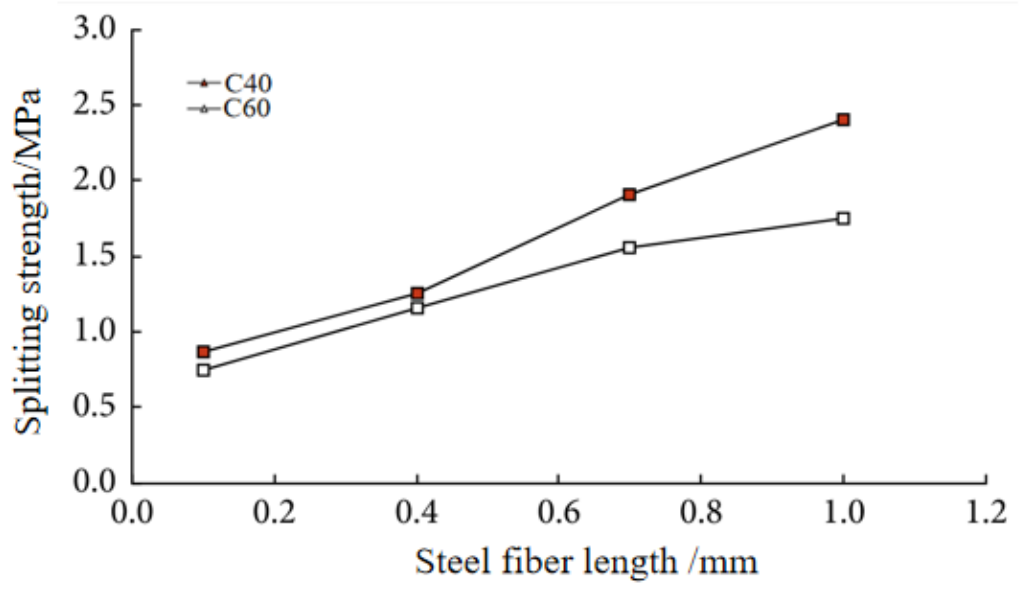

Figure 2. Effect of steel fiber length on splitting strength

The splitting failure state of concrete is shown in Figure 3. After the failure of plain concrete in the splitting tensile test of concrete, the crack developed rapidly and breaks into two halves. There was a splitting sound in the cracking process, and the cube specimen was divided into two parts, as shown in Figure 3(a). Because of the high tensile strength and large fiber diameter of steel fiber concrete, the fiber on the fracture surface of fiber concrete was pulled out and destroyed. As shown in Figure 3(b), the cube specimens of fiber concrete were not separated from the fracture surface, but were still connected as a whole, and there were many micro-cracks, which showed that the shortcomings of high brittleness and low toughness of concrete had been significantly improved.

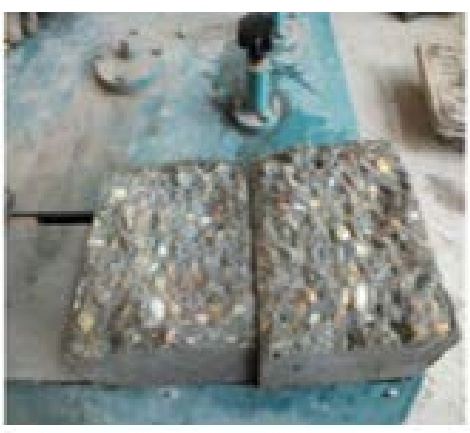

(a) Plain concrete

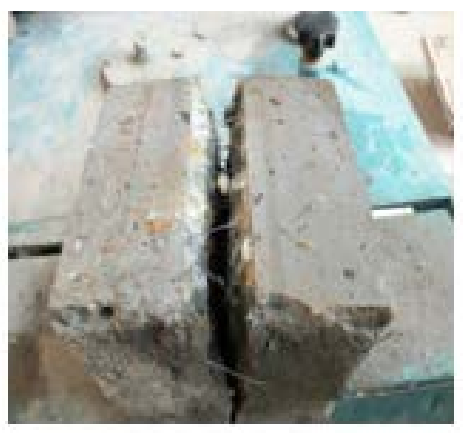

(b) Fiber reinforced concrete

Figure 3. Split failure state of concrete 


\subsubsection{Results of Splitting Tensile Test of Concrete}

It can be seen from the splitting tensile strength of concrete in Figure 4 that the splitting tensile strength of concrete gradually increased with the increase of steel fiber content. When the volume content of steel fiber was between $1.2 \%$ and $2.4 \%$, the splitting tensile strength of concrete did not change obviously with the content of steel fiber. When the volume content of steel fiber increased from $1.2 \%$ to $2.4 \%$, the splitting tensile strength increased only by $3.4 \%$. However, when the volume content of steel fiber was 3.8\%, the splitting tensile strength greatly improved.

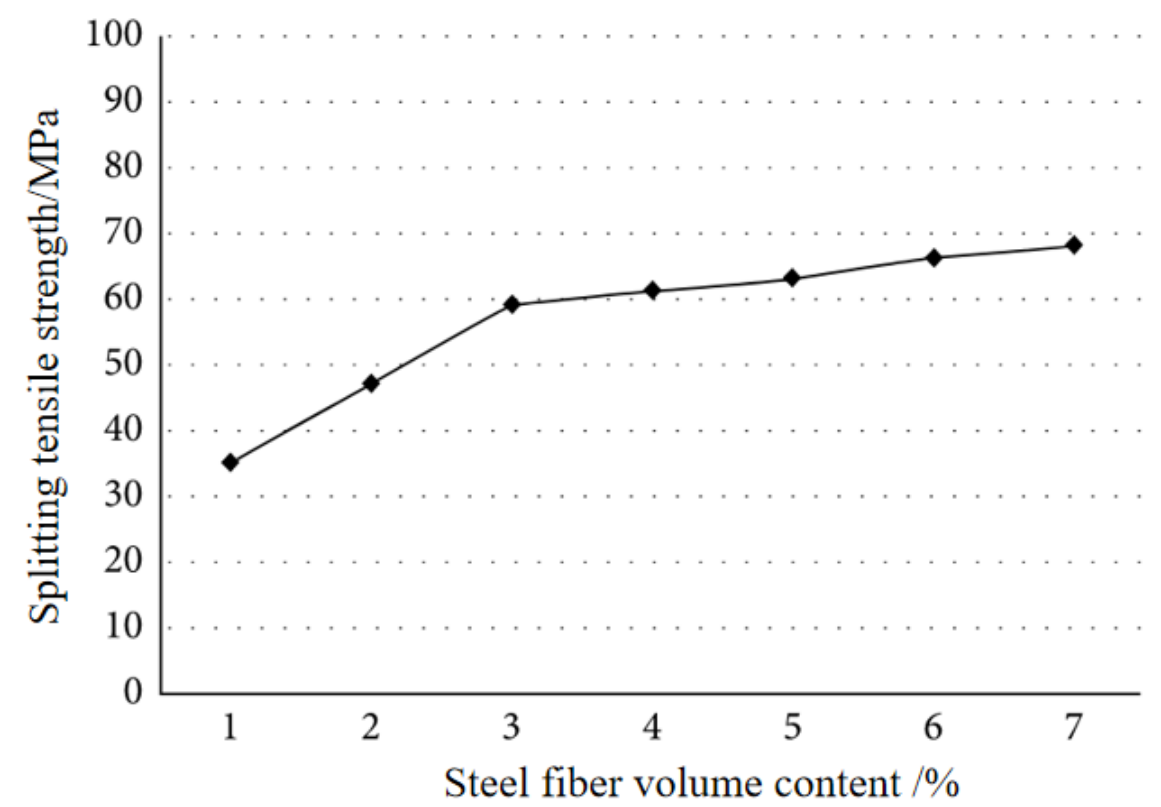

Figure 4. Split tensile strength of concrete with different steel fiber volume content

\subsubsection{Influence of Steel Fiber on Bending Toughness of Concrete}

It can be seen from the data in Table 4 that the initial cracking strength, ultimate strength, flexural toughness index and flexural toughness ratio of concrete gradually increased with the increase of steel fiber content. When the volume content of steel fiber was $1.3 \%$, the indexes of $50 \mathrm{~mm}$ long fiber concrete further improved than those of $35 \mathrm{~mm}$ short fiber concrete. Compared with plain concrete of the corresponding grade, the steel fiber reinforced concrete with $1.3 \%$ content and $60 \mathrm{~mm}$ length had the largest improvement in bending ultimate strength, C40 and C60 concrete increased by $107.8 \%$ and $97.3 \%$ respectively, and the bending toughness indexes I5, I10 and I20 of C40 and C60 concrete increased by 5.16, 10.97, 24.72 times and 5.01, 10.98, 24.13 times, respectively compared with plain concrete. 
Table 4 Bending performance test results

\begin{tabular}{ccccccccc}
\hline Grade & $\begin{array}{c}\text { Doping } \\
\text { amount } \\
\text { /\% }\end{array}$ & $\begin{array}{c}\text { Initial } \\
\text { cracking } \\
\text { strength/MPa }\end{array}$ & $\begin{array}{c}\text { Ultimate } \\
\text { strength } \\
\text { /MPa }\end{array}$ & $I_{5}$ & $I_{10}$ & $I_{20}$ & $f_{e}$ & $R_{e}$ \\
\hline C40 & 0.3 & 4.03 & 4.03 & 1.00 & 1.00 & 1.00 & - & - \\
& 0.5 & 5.33 & 5.88 & 3.62 & 14.24 & 14.63 & 2.32 & 0.84 \\
& 0.7 & 5.41 & 6.34 & 5.41 & 15.93 & 15.36 & 4.26 & $0 . .93$ \\
& 1.0 & 5.82 & 6.17 & 5.06 & 17.25 & 18.44 & 6.93 & 1.12 \\
& 1.3 & 6.81 & 7.11 & 6.36 & 18.49 & 19.63 & 7.88 & 1.27 \\
C60 & 0.3 & 5.56 & 5.56 & 1.00 & 1.00 & 1.00 & - & - \\
& 0.5 & 5.47 & 6.37 & 8.63 & 13.63 & 12.21 & 2.63 & 0.34 \\
& 0.7 & 6.93 & 7.51 & 8.57 & 14.72 & 12.86 & 4.12 & 0.61 \\
& 1.0 & 7.88 & 8.64 & 9.03 & 17.82 & 14.32 & 5.17 & 0.81 \\
& 1.3 & 7.83 & 8.82 & 10.24 & 19.01 & 15.01 & 6.83 & 1.07 \\
\hline
\end{tabular}

\subsubsection{Concrete slump}

The slump of steel fiber reinforced concrete mixture decreased with the increase of steel fiber content. The slump of the mixture directly reflected the fluidity of the concrete mixture, and the fluidity depended on the water consumption of the mixture or the content of cement slurry. In the steel fiber concrete mixture, the larger the steel fiber content was, the more the cement slurry used to coat the steel fiber and the surface of coarse and fine aggregates were. When the cement content per unit volume is the same, the fluidity of concrete mixture became worse with the increase of steel fiber content.

\subsubsection{Hole Structure}

The pore structure parameters of steel fiber reinforced concrete after curing for 30 days measured by the mercury intrusion method are shown in Table 5 .

Table 5 Pore structure parameters of steel fiber reinforced concrete

\begin{tabular}{llllll}
\hline Parameter & PC & SFC-0.5 & SFC-1.0 & SFC-1.5 & SFC-2.0 \\
\hline Total porosity & 14.36 & 14.04 & 13.07 & 11.79 & 14.71 \\
\hline Total pore volume 0.0742 & 0.0561 & 0.0517 & 0.0511 & 0.0782 \\
\hline Total pore area & 24.17 & 18.66 & 16.49 & 13.27 & 19.41 \\
\hline
\end{tabular}

When the content of steel fiber was in the range of $0 \sim 1.5 \%$, with the increase of steel fiber, the total porosity, pore volume and pore area of concrete decreased, and the pore structure of concrete improved. When the content of concrete was $1.5 \%$, the total porosity of concrete decreases by $30.13 \%$, and the pore volume and pore area decreased by $27.04 \%$ and $41.68 \%$, respectively. When the content of steel fiber increased to $2.0 \%$, the total porosity, pore volume and pore area of concrete increased. Generally speaking, in the forming process of concrete structure, concrete will shrink due to water loss and other reasons. When the tensile strength of concrete is less than the shrinkage stress, cracks will appear in concrete. 


\subsection{Discussion}

Concrete is a composite material composed of coarse and fine aggregates, cement paste and cement paste-aggregate interface transition zone. The three phases in concrete have different strengths due to their different material compositions and structures. Generally speaking, the strength of aggregate is greater than that of cement paste and cement paste-aggregate interface transition zone, while the strength of cement paste-aggregate interface transition zone is weaker than that of cement paste [13-14]. When there are small cracks in concrete material, the bonding force between steel fiber with high elastic modulus and concrete matrix has a certain effect of resisting cracks. Under the action of external load, some slight cracks will first appear in the specimen, with small crack tip size and highly concentrated stress. Steel fibers are randomly distributed in concrete, and the more the number of steel fibers per unit volume, the greater the probability of cracks crossing steel fibers in the development process, and the more obvious the constraint effect of steel fibers on crack development [15]. Therefore, within a certain range, the steel fiber with the same length and large ratio of length to diameter has better crack resistance effect. When the volume content of steel fiber increases from $1.5 \%$ to $2.5 \%$, the increase of splitting tensile strength slows down, which may be related to the uneven distribution of steel fiber. During the whole loading of the beam in this laboratory, there are cracks on the front and back sides of the beam. When observing cracks, attention should also be paid to the development of cracks at beam points. If the cracks at the bottom of the beam can connect the cracks on the front and rear faces of the beam, it can be considered that the cracks on the front and rear faces of the beam form a through face inside the beam [16].

Mixing technology of concrete is an important factor affecting the uniformity of fiber distribution in concrete. Mechanical mixing is superior to manual mixing in terms of workability of concrete and dispersion of fiber, and the labor intensity of manual mixing is high. On the one hand, the addition of steel fiber causes more initial cracks in concrete, increases the initial defects of concrete, and reduces the compressive strength of concrete. On the other hand, steel fiber can prevent cracks in concrete, thus improving the compressive strength of concrete [17]. Therefore, the influence of steel fiber on the compressive strength of concrete is not significant. The residual compressive strength ratio of plain concrete decreases rapidly, while the residual compressive strength ratio of concrete mixed with steel fiber increases greatly. However, there is no strict linear growth relationship between the content of steel fiber and the improvement of residual compressive strength ratio [18]. This effect gradually tends to a certain stable value, especially in the compressive strength curve, which shows that the fiber reinforcement effect is limited, so simply increasing the fiber content is not the best measure to improve the material strength [17]. In actual production, it should also be combined with the economic situation to obtain the best content.

According to the test results, we can see the characteristics of the full curve of concrete: the slope of the rising section of the curve changed little, the stress and strain basically maintained the linear elastic relationship, and the elastic proportional limit was about $85 \%$ of the peak stress, which was much higher than that of ordinary concrete by $40 \%-50 \%$. 
Generally, the number of cracks increased and the width of cracks decreased, and the width of most cracks was $0.1 \mathrm{~mm}$ : When the length of micro-cracks was longer than the fiber spacing, the cracks spanned steel fibers, and the steel fibers bridging the cracks bore and transferred the internal stress of concrete caused by shrinkage and other factors, so that the stress field in concrete was continuous and uniform, and the stress concentration at the tip of micro-cracks was passivated, thus restricting the further expansion of cracks [19]. Compared with the tensile-compressive ratio of matrix concrete, the tensile-compressive ratio of concrete increases by $50 \%-106 \%$, which indicated that the brittleness and toughness of matrix concrete greatly improved after adding steel fiber. With the increase of steel fiber volume ratio, the cracking load and bearing capacity of beams improved on the whole [20]. This was because: after being stirred in concrete, steel fibers were distributed in a three-dimensional random way in the concrete mixture, forming a spatial network structure, which played a supporting role for aggregates, and the fibers were thin and had a large specific surface area, which led to the thinning of the cement slurry layer surrounding aggregates and fibers, and reduced the lubrication effect of cement slurry; It further showed that under the action of high temperature, steel fiber mainly played a role by preventing the development of concrete temperature cracks and enhancing the crack resistance, and the effect of reducing the tensile strength after high temperature was less than the compressive strength [21].

During the splitting process of concrete cube specimen, several tiny cracks appeared in the loading surface of the specimen at the initial stage. With the increase of load, the cracks gradually developed, and finally ran through the whole specimen, splitting the specimen into two parts which were not completely separated, and some steel fibers were still attached to the concrete on both sides in the section [22]. After reaching the peak stress, it entered the stage of crack instability and propagation, and the crack developed rapidly, and the splitting sound in the specimen became more obvious, which indicated that steel fiber played a more significant role in cracking resistance. In the descending section of the curve, the slope was negative; it first reached an inflection point, then reached the point of maximum curvature, and finally, the curve slowly descended, tended to be flat, and entered the stage of residual strength [23]. The workability and workability of the fresh concrete mixture did not changed obviously, and the mixing of steel fiber did not change the mixture ratio of raw materials. Moreover, for the damaged specimens, steel fiber concrete specimens were often broken but not scattered after reaching the ultimate load, which changed the cracking when concrete was damaged [24].

\section{CONCLUSION}

Based on the action mechanism of steel fiber, the relationship between stress state and energy consumption of steel fiber in concrete is theoretically explained, which shows that fiber can bear tensile force well in concrete, while concrete exerts its compressive strength.

Compared with plain concrete, the slump of concrete with steel fiber obviously reduces, and the higher the content is, the smaller the slump is, and the cohesion and water retention have little change; After the concrete is mixed with the fiber in this paper, the slump decreased, but it does not affect the compactness of fiber concrete vibrating. 
The addition of steel fiber can improve the compressive strength, splitting strength and flexural strength of concrete. When the volume content of steel fiber increases from $0.5 \%$ to $2.5 \%$, the cube compressive strength increases by $7.44 \% \sim 23.39 \%$ and the axial compressive strength increases by $8.02 \% \sim 24.61 \%$.

The effect of steel fiber on axial compressive strength of concrete is similar to that of cube compressive strength. In order to achieve the ideal reinforcement effect, with the increase of the strength grade of concrete matrix, the optimum content of steel fiber should also be increased. Although steel fiber does not improve the axial compressive strength obviously, it significantly improves its failure mode.

The effect of steel fiber on axial compressive strength of concrete is similar to that of cube compressive strength. In order to achieve the ideal reinforcement effect, with the increase of the strength grade of concrete matrix, the optimum content of steel fiber should also be increased. Although steel fiber does not improve the axial compressive strength obviously, it significantly improves its failure mode.

When the volume content of steel fiber changes from $1.0 \%$ to $2.0 \%$, the splitting tensile strength and flexural strength of concrete do not change obviously with the content of steel fiber, but when the volume content of steel fiber is 3.5\%, the splitting tensile strength and flexural strength of concrete are greatly improves. With the increase of steel fiber content, the splitting tensile strength is not obvious, but the flexural strength is still greatly improves. For concrete members with high tensile or ductility requirements, it is suggested that the steel fiber content should be appropriately increased and the steel fiber volume content should be about $3.0 \%$.

\section{ACKNOWLEDGEMENTS}

The authors acknowledge the Research start up fund for high level talents of Bengbu University (BBXY2019KYQD05).

\section{REFERENCES}

[1] Yang, J.M., D.Y. Yoo, and Y.C. Kim, Mechanical Properties of Steam Cured HighStrength Steel Fiber-Reinforced Concrete with High-Volume Blast Furnace Slag. International Journal of Concrete Structures \& Materials, 2017. 11(2): p. 391-401.

[2] Abbass, W., M.I. Khan, and S. Mourad, Evaluation of mechanical properties of steel fiber reinforced concrete with different strengths of concrete. Construction \& Building Materials, 2018. 168(APR.20): p. 556-569.

[3] Zheng, Y., X. Wu, G. He, and Q. Shang, Mechanical Properties of Steel Fiber-Reinforced Concrete by Vibratory Mixing Technology. Advances in Civil Engineering, 2018. 2018(PT.5): p. 1-11.

[4] Hazimmah, S.D.S., and H.T. Cheng, Mechanical Characterization of Steel Fibre Reinforced Acrylic Emulsion Polymer Modified Concrete. Open Journal of Civil Engineering, 2016. 6(1): p. 8-18. 
[5] Kan, C.Q., X.L. Kang, and R. Pan, Mechanical properties of self-comparing concrete by steel fiber and glass fiber. Shanxi Architecture, 2017. 043(007): p. 104-106.

[6] Du, J., C. Tang, B. Jia, and D. Zhang, Preparation and Long-Term Stability Study of Steel Fiber/Graphite Conductive Concrete. Key Engineering Materials, 2016. 680: p. 361-364.

[7] Algburi, A.H.M., M.N. Sheikh, and M.N.S. Hadi, Mechanical properties of steel, glass, and hybrid fiber reinforced reactive powder concrete. Frontiers of Structural and Civil Engineering, 2019. 13(4): p. 998-1006.

[8] Ramesh, R.B., O. Mirza, and W.H. Kang, Mechanical properties of steel fiber reinforced recycled aggregate concrete. Structural Concrete, 2019. 20(2): p. 745-755.

[9] Noaman, A.T., B.H. Abu Bakar, and H. Md. Akil, Investigation on the mechanical properties of rubberized steel fiber concrete. Engineering Structures \& Technologies, 2017. 9(2): p. 79-92.

[10]Fu, C., H. Ye, K. Wang, K. Zhu, and C. He, Evolution of mechanical properties of steel fiber-reinforced rubberized concrete (FR-RC). Composites B Engineering, 2019. 160(MAR.1): p. 158-166.

[11]Babaie, R., M. Abolfazli, and A. Fahimifar, Mechanical properties of steel and polymer fiber reinforced concrete. Journal of the Mechanical Behavior of Materials, 2019. 28(1): p. 119-134.

[12] Khan, M., M. Cao, and M. Ali, Effect of basalt fibers on mechanical properties of calcium carbonate whisker-steel fiber reinforced concrete. Construction and Building Materials, 2018. 192: p. 742-753.

[13] Liu, W.S., X.Y. Chen, X.F. Liu, and L.H. Lu, The basic mechanical properties of tailing and steel fiber shot concrete. Shanxi Architecture, 2016. 042(033): p. 115-117.

[14] Sengul, O., Mechanical properties of slurry infiltrated fiber concrete produced with waste steel fibers. Construction and Building Materials, 2018. 186(OCT.20): p. 1082-1091.

[15] Lee, J.C., Mechanical Properties and Neutron Shielding Rate of Concrete with Borosilicate-Glasses and Amorphous Boron Steel Fiber. Journal of the Korean Recycled Construction Resources Institute, 2016. 4(3): p. 269-275.

[16] Abid, M., X. Hou, W. Zheng, and G.Q. Waqar, Mechanical properties of steel fiberreinforced reactive powder concrete at high temperature and after cooling. Procedia Engineering, 2017. 210: p. 597-604.

[17] Cui Zhenglong, Tong Huabin, Wu Xiangyu, et al. Research on the influence of the shape and properties of recycled coarse aggregate on the mechanical properties of concrete. Bulletin of the Chinese Ceramic Society, vol. 33, no. 9, pp. 2429-2433, 2014.

[18] A.M. Marques, J.R. Correia, J. de Brito. Post-fire residual mechanical properties of concrete made with recycled rubber aggregate. Fire Safety Journal, vol. 58, no. 5, pp. 4957, 2017.

[19] Madandoust R, Ghavidel R. Mechanical properties of concrete containing waste glass powder and rice husk ash. Biosystems Engineering, vol. 116, no. 2, pp. 113-119, 2013.

[20] Zhang Lanfang, Yin Yulong, Liu Jingwei, et al. Research on the mechanical properties of basalt fiber reinforced concrete. Bulletin of the Chinese Ceramic Society, no. 11, pp. 2834-2837, 2014. 
[21] Chen Zongping, Zhou Chunheng, Chen Yuliang, et al. Experimental study on mechanical properties of recycled pebble aggregate concrete. Journal of Building Materials, vol. 17, no. 3, pp. 465-469, 2014.

[22] Gudonis E, Kacianauskas R, Gribniak V, et al. Mechanical Properties of the Bond Between GFRP Reinforcing Bars and Concrete. Mechanics of Composite Materials, vol. 50, no. 4, pp. 457-466, 2014.

[23] Jonbi, Arini, R.N., M. Permatasari, and P.H. Simatupang, Comparative of the Use of Carbon and Steel Fiber to the Mechanical Properties of Self Compacting Concrete. Solid State Phenomena, 2020. 304.

[24] Huang, J., Y. Zhang, Y. Tian, and H. Xiao, Research on the Dynamic Mechanical Properties and Constitutive Models of Steel Fiber Reinforced Concrete and Polypropylene Fiber Reinforced Concrete. Advances in Civil Engineering, 2020. 2020(6): p. 1-17. 
